\title{
Sector inmobiliario y estructura urbana en la ciudad de Puebla, 1900-2010
}

\author{
Real Estate Sector and Urban Structure \\ in the City of Puebla, 1900-2010
}

\author{
Lorena Cabrera \\ (1) 0000-0002-2955-1936 \\ Universidad Iberoamericana Puebla, México \\ lorecamo@gmail.com \\ Javier Delgado \\ Universidad Nacional Autónoma de México, México \\ interfase7@gmail.com.mx
}

Resumen: El objetivo del ensayo es ofrecer una lectura simultánea del impacto del capital inmobiliario sobre la estructura urbana de Puebla entre 1900 y 2010 a escala metropolitana. Este enfoque metodológico de largo plazo proporciona un contexto general, útil para entender la complejidad de una urbe que ha incrementado exponencialmente su superficie y parque habitacional al mismo tiempo. Su originalidad descansa en el enfoque analítico adoptado el cual permite entender la repercusión espacial del ajuste de políticas nacionales y locales, sistematizar datos aislados sobre la conformación de distintas formas de agrupación habitacional, y mostrar el cambio de una estructura urbana compacta a otra dispersa. Las principales aportaciones son una síntesis de la territorialidad de esos procesos, algunas ideas seminales sobre el papel del mercado inmobiliario y la relación de fuerzas y presiones sociales ejercidas, así como delinear conjeturas que pueden ser útiles para la discusión de políticas urbanas menos desafortunadas.

Palabras clave: mercado inmobiliario; vivienda; promotor; estructura urbana; Puebla. 
Abstract: The objective of the essay is to offer a simultaneous interpretation of the impact of real estate capital on the urban structure of Puebla between 1900 and 2010 at the metropolitan level. This long-term methodological approach provides a general context, useful for understanding the complexity of a city that has exponentially increased its area and housing stock at the same time. Its originality lies in the analytical approach adopted, making it possible to understand the spatial repercussion of the adjustment to national and local policies, systematize isolated data on the creation of different forms of housing groups, and showed the change from a compact to a scattered urban structure. The main contributions are a synthesis of the territoriality of these processes, some seminal ideas about the role of the real estate market and the relationship of social forces and pressures exerted, as well as an outline of conjectures that may be useful for discussing less successful urban policies.

Key words: real-estate market; housing; promoter; urban structure; Puebla.

Fecha de recepción: 24 de mayo de 2017 Fecha de aceptación: 25 de enero de 2018

\section{PRESENTACIÓN}

$E^{1}$ 1 mercado inmobiliario habitacional desempeña desde el siglo pasado un papel clave en la configuración y expansión urbana de la ciudad de Puebla a través de la revalorización del suelo. Nos interesa seguir los cambios en los factores básicos de ese proceso como la propiedad del suelo, los inversionistas, los usuarios y las más elaboradas formas de la promoción inmobiliaria actual.

Las huellas que la liberalización y privatización del mercado del suelo han dejado en apenas 20 años son profundas. No se trata de acciones aisladas sino el resultado de ensayos previos en la instrumentación de políticas urbanas cuya normatividad le ha allanado el acceso al suelo y puesto a su disposición medios financieros para su operación, al tiempo que han apoyado el consumo de sectores sociales que pueden pagarlo. Sus efectos territoriales son de cierta forma irreversibles, pues no es fácil modificar el entorno construido durante un largo tiempo como el que aquí se aborda. En cambio, es factible redimensionar socialmente el papel de la promoción privada en las políticas y procesos de producción habitacional. 
Iniciamos este ensayo con una breve revisión de la literatura sobre el tema, seguido de los antecedentes de la urbanización poblana; en seguida se exponen los cambios experimentados a lo largo del siglo $\mathrm{xx}$, sintetizando la territorialización de esos procesos, especialmente de 1990 a 2010 cuando la expansión de la periferia asociada a la actividad inmobiliaria formal fue más intensa. Por último, se sugieren algunas líneas de investigación que pueden ser útiles para estudios más detallados y periodos más cortos.

\section{REVISIÓN DE LA LITERATURA}

En una economía de mercado, la configuración de la ciudad es resultado de procesos de producción del espacio urbano indispensable como condición, medio y producto para la reproducción de capital (Harvey, 2007; Lefebvre, 2013; Soja, 1993). Desde esta perspectiva analítica se ha investigado la influencia del capital y de los actores que producen el espacio construido (Topalov, 1974, 1979) y, por lo tanto, su conceptualización como una construcción social (Castells, 1974; Harvey, 2007; Lefebvre, 2013).

Para muchos, la actuación de los agentes económicos, así como la intervención estatal, son los principales factores que transforman la estructura urbana (Feagin, 1979; Harvey, 1985). Es así que los actores sociales consumen y determinan el marco construido, mediante sus decisiones, preferencias o posibilidades (Bourdieu, 2001), a través de movimientos sociales urbanos reivindicativos (Castells, 1974).

Algunos autores resaltan las huellas de un legado histórico en la estructura misma de la ciudad para la cual las formas de organizarse socialmente le son siempre propias (Jaramillo, 2009). La idea de que los procesos históricos transcurren en una larga duración es una reflexión original de Braudel (1970). Con ella se pueden explicar los cambios y continuidades que atendidos coyunturalmente se quedan cortos. Pero tal enfoque teórico es idóneo para explicar el transcurrir del espacio urbano, ya que la ciudad preserva zonas con valor histórico y las combina con los nuevos espacios que pueden dar continuidad o bien romper su estructura tradicional.

Para emplear ese esquema analítico es necesario contar con datos pertinentes sobre un mismo objeto de estudio - mercado inmobiliario en nuestro caso-, para identificar inflexiones claves en la continuidad espacial, en distin- 
tos momentos históricos, bajo sistemas políticos y económicos distintos, pero que ejemplifican muy bien las rupturas. O sus continuidades.

Para facilitar el análisis de la política urbana, algunos autores se han centrado en el papel de la vivienda como política de ordenación del espacio y como bien de consumo suministrado a la población para asegurar la reproducción de la fuerza de trabajo, así como la repercusión de esas relaciones de fuerzas sociales en las políticas que deben regularlas (Castells, 1974; Lojkine, 1979). Es así como el desempeño del capital inmobiliario expresa esa relación social y las contradicciones que se generan entre los diversos agentes que producen el espacio urbano, y que se acomodan a los requerimientos de cada fase del desarrollo del capital y tienen al suelo como soporte físico del proceso (Jaramillo, 2009). Por su parte, el Estado, al generar las condiciones políticas, jurídicas y materiales para el desarrollo del proceso económico, actúa también como intermediario en las contradicciones que surgen en los diferentes niveles de consumo.

En esta perspectiva, y dentro del contexto latinoamericano, se ha prestado más atención a las distintas formas de producción de vivienda, ya sea por encargo, autoconstrucción, promoción capitalista o promoción pública (García, 1988; Jaramillo, 2009; Pradilla, 1976; Schteingart, 1982, 1989). Bajo ese enfoque es posible entender el papel, relaciones y estrategias de los actores en los mercados de suelo y de vivienda, los capitales que intervienen en la urbanización y los efectos de los cambios estructurales en el mercado inmobiliario.

Pero aun así falta exponer los efectos territoriales de esos procesos económicos. Existe un consenso académico sobre la vigencia del modelo teórico centro-periferia formalizado por Alonso (1964) desde la segunda mitad del siglo pasado. Su pertinencia nos permite explicar la dinámica en la estructura de las ciudades bajo sistemas económicos muy disímbolos como son los de mercado y los de regulación estatal.

El modelo centro-periferia se refiere a la dinámica del proceso y no a su morfología, como con frecuencia se confunde. La dinámica expresa la velocidad y dirección de la expansión a partir del núcleo urbano original hacia las zonas aledañas. Dicha dinámica se ve constreñida por factores geográficos -como el relieve-, o sociales -como la tenencia-, y la política, lo que en conjunto moldea la forma de la ciudad.

En el contexto latinoamericano se han propuesto modelos de estructura urbana propios (Borsdorf, Hidalgo y Sánchez, 2007; Gormsen, 1981), pero los esfuerzos por espacializar esos procesos socioeconómicos y políticos son me- 
nos frecuentes. En el caso de Puebla, Flores (1993) realizó un seguimiento de los cambios en la estructura territorial del área metropolitana y Germain y Pòlese (1996) realizaron un interesante análisis factorial de la segregación residencial.

En este ensayo presentamos una interpretación propia de esas continuidades y rupturas con base en la recopilación exhaustiva de cómo y en dónde se fueron construyendo fraccionamientos en la ciudad a lo largo del siglo $\mathrm{xx}$. Esta síntesis sugiere su consideración o pertenencia en distintas políticas y lineamientos de planeación urbana gubernamental. Es necesario estudiar con mayor profundidad esos quiebres, sobre todo de las coyunturas, contingencias y actores específicos en cada transición que pudieran cuestionar los resultados obtenidos.

\section{LA CONFORMACIÓN DE PUEBLA EN EL LARGO PLAZO}

Desde su fundación en 1531 en medio de importantes cabeceras indígenas como Cholula, Tlaxcala y Huejotzingo, la ciudad fue el principal centro regional para la organización y control territorial, tanto civil como religioso.

Con una localización estratégica entre la capital virreinal, el Golfo de México y el sureste del país, un poblamiento inicialmente denso y una economía próspera, llegó a ser la segunda ciudad del país durante los siglos XVII y XVIII (Lomelí, 2010). Erigida a los pies de la Sierra Nevada y del volcán de la Malinche, sobre la llanura lacustre en la cuenca del río Atoyac que, junto con el río San Francisco acunaron la traza original. Desde un inicio, la ciudad estuvo dividida entre una traza central ocupada por españoles y barrios indígenas en la periferia, lo que facilitó el control social. Para fines del siglo XIX esa división se reproducía en nuevos barrios para los sectores altos y grupos de extranjeros, por un lado, y barrios populares, por el otro.

Hasta principios del siglo xx conservó su traza original, sobre una retícula rectangular homogénea, compacta y sin murallas, propia del modelo urbanístico novohispano (Méndez, 1989). La propiedad del suelo y la producción privada fueron factores cruciales en la producción de los nuevos espacios que comenzaron a ser demandados, con una intervención estatal mínima. A partir de entonces, el sector inmobiliario ha pasado por distintas etapas hasta llegar al reciente periodo de desregulación, en el cual ha alcanzado un claro predominio sobre las operaciones en el mercado del suelo y la conformación del espacio urbano. 
Para exponer la evolución del sector inmobiliario se diferenciaron cinco periodos: 1) operaciones antes de los años cuarenta; 2) penetración del sector inmobiliario en los esquemas de regulación del suelo y planeación urbana entre 1940 y 1960; 3) articulación funcional entre sistemas financieros y políticas habitacionales de 1960 a 1974; 4) maduración del sector inmobiliario en la ciudad de 1974 a 1990, y 5) desregulación neoliberal y promoción inmobiliaria de 1990 a 2010. Veamos más de cerca cada fase de esa evolución.

\section{LA OPERACIÓN INMOBILIARIA ANTES DE 1940}

Tras la revolución, la reforma agraria y la creación de los ejidos, ${ }^{1}$ con la política urbana instrumentada hasta 1940 se intentó consolidar el aparato institucional y vigorizar el desarrollo industrial mediante obras de infraestructura y comunicaciones. Los problemas urbanos no eran el foco principal y la política de vivienda fue muy limitada (Castells, 1977).

Las primeras compañías inmobiliarias poblanas se fundaron entre 1880 y 1910. La incipiente operación inmobiliaria privada consistía en comprar legalmente terrenos a bajo precio en las orillas de la ciudad, en pequeñas propiedades privadas, dividirlos en lotes y ponerlos a la venta con apenas un pequeño margen de ganancia (Melé, 1994). En muchos casos, los mismos pobladores formaban una sociedad inmobiliaria propia, y otras veces, los promotores se asociaban con los propietarios del suelo (Vélez, 2007).

En el centro de la ciudad los antiguos propietarios subdividían sus viejas y deterioradas casonas para rentarlas, a muy bajo precio, como vecindades que eran ocupadas por varias familias (Ovalle, 1982). Al mismo tiempo, la competencia comercial y de servicios para instalarse en el centro, encareció su precio e hizo volver la mirada de la clase media emergente hacia las afueras de la ciudad. Con su aspiración a la modernidad y una preferencia por ocupar viviendas nuevas, se erigieron colonias y fraccionamientos, en una primera periferia urbana. En esa época se podía adquirir una vivienda mediante el pago de contado, accesible a sectores de ingresos altos y medios para habitarla o rentarla (Montero, 2002a), o mediante el autofinanciamiento y la autocons-

\footnotetext{
${ }^{1}$ En Puebla se formaron al norponiente San Pablo Xochimehuacán (1921), Sanctorum y Coronango (1930); al poniente Romero Vargas y La Libertad (1925). Los restantes son de 1935 y se ampliaron después de 1960 (Melé, 1994).
} 
trucción para la población de menos recursos en áreas rurales de la periferia cercana (Barragán, 1994).

Aunque se tienen registros de colonias construidas a fines del siglo XIX, fue entre 1900 y 1940 que se lotificaron tierras en todas las direcciones de la ciudad. ${ }^{2}$ Estas provenían de los ranchos y haciendas cercanas y apuntaron a distintos sectores sociales. El Molino de San Francisco fue el primer fraccionamiento residencial propiamente moderno construido en 1940, al oriente de la ciudad. Al mismo tiempo, se crearon poblamientos populares a partir de grandes extensiones de suelo privado en la periferia. Su modus operandi estriba, como ahora, en una gestión forzada a través de líderes sindicales, gremiales o de otras agrupaciones políticas. Estas áreas carecían de un plan urbanístico definido, no había títulos de propiedad, ni servicios básicos (Montero, 2002b). Mientras, el Estado estaba ocupado en construir una economía nacional y un aparato de control.

Después del periodo armado de la revolución y en un contexto nacional de cambios institucionales se impulsaron instrumentos jurídicos para controlar la expansión a través de regular el mercado de suelo. ${ }^{3}$ A pesar de que existían ya procedimientos jurídicos para expropiar, indemnizar, poseer y lotificar tierras, la respuesta gubernamental se limitó -hasta mediados de los años treinta- a higienizar y mejorar la imagen urbana de la ciudad (Montero, 2006) con lo cual difícilmente podría controlarse la urbanización de la periferia. Desde entonces, la actividad inmobiliaria privada carecía de un concepto integral de ciudad y, por el contrario, favoreció una ocupación de baja densidad que no ha podido revertirse.

La población de la ciudad se mantuvo relativamente estable hasta que terminó el conflicto armado, pues de 98000 habitantes en 1900 (Contreras, 1984) se pasó a 138000 en 1940, mientras las 1060 ha del área urbana llegaban apenas a 1120 hectáreas en 1940 (véase Anexo 1).

${ }^{2}$ Colonias precursoras fueron Los Remedios (1883), la Magdalena (1898), Pensador Mexicano (1884), Zaragoza (1879), Periodista (1894), Rancho Nuevo y San Sebastián (1899), (Montero, 2002a). Después de 1900, la Azteca, Hogar del Empleado, Amor, Del Maestro Federal, Santa María, Anzures, Cuauhtémoc, Lomas del 5 de Mayo, Moctezuma, Vista Hermosa, América Norte y Sur, Azcarate, Carril de la Rosa, Cristóbal Colón, Humboldt Norte y Sur (DIAU, 2010).

${ }^{3}$ Decreto XXVI del Congreso del Estado (1923), que facultó al estado para establecer colonias alrededor de los centros de población y su posterior reglamento correspondiente (1931). 


\section{PRIMEROS ESQUEMAS DE REGULACIÓN DEL SUELO Y FLORECIMIENTO INMOBILIARIO, 1940-1960}

Como parte de la institucionalización del nuevo régimen se conjugaron el interés público por regular la expansión urbana y la lógica económica que guiaba la base productiva en un proceso de sustitución de importaciones y desarrollo de la industrialización que impactó al capital inmobiliario.

Para orientar el ensanche de las ciudades se adoptó la medida de zonificar áreas relativamente homogéneas (zoning) que tan buenos frutos daba en Europa, pero sin fijar medidas para regular la construcción, ni la instrumentación de nuevos programas de vivienda -mera declaración del Estado para tocar el problema- $y$, menos aún, los distintos esquemas de financiamiento o la redefinición de la relación entre propiedad del suelo y capital promotor. En particular, la Ley de Fraccionamientos Urbanos de la ciudad de Puebla (1940), transfirió al municipio la facultad para autorizar nuevos asentamientos. Se concibió como un instrumento valioso para ordenar localmente el espacio urbano, pero sin recursos ni capacidad operativa para llevarlo a cabo.

Ante la debilidad política de los municipios, el capital inmobiliario aprovechó la coyuntura que le ofrecían las nuevas condiciones al no encontrar resistencia. Todavía más, los fraccionadores obtuvieron ganancias adicionales al ser el municipio quien debía asumir los costos de urbanización de los terrenos supuestamente a través de impuestos aplicados a los predios urbanos, al comercio y a la industria (Vélez, 2007). Una vez allanado el camino jurídico y económico, el número de sociedades fraccionadoras aumentó de 18 en 1939 a unas 46 a finales de los años sesenta (Montero, 2002a). Al ocupar terrenos de acuerdo con la oferta, iban dejando extensos vacíos urbanos pues la idea de conjunto no era responsabilidad suya.

Si hasta 1950 los fraccionamientos de la primera periferia ${ }^{4}$ se habían ajustado a la traza original, sin romper su compacidad y continuidad, la febril actividad inmobiliaria de los años cincuenta fue un parteaguas en la conformación de la ciudad (Hernández et al., 2009; Melé, 1994; Montero, 2002a, 2002b, 2006; Rivas, 2008; Salamanca, 2005) (véase mapa 1).

Los nuevos fraccionamientos, ${ }^{5}$ incluso los que operaban dentro del mercado formal, rompieron la regularidad espacial, aprovechando vialidades

${ }^{4}$ Gabriel Pastor, Volcanes, Bella Vista, Bugambilias.

${ }^{5}$ Mayorazgo, Leobardo Coca, Patrimonio, Castillotla. 


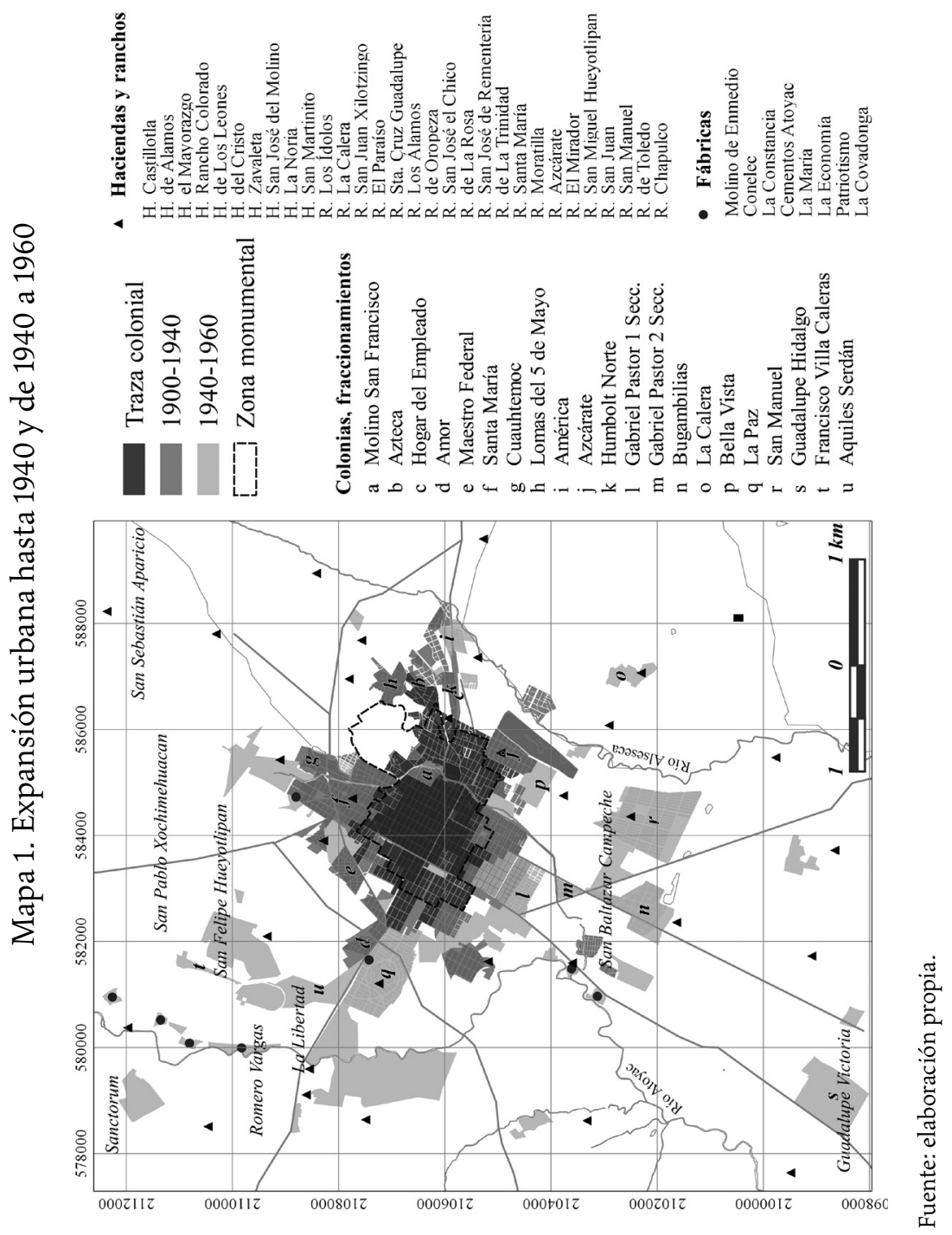


primarias como la 11 Sur, Boulevard Valsequillo y la 16 de Septiembre. Construidos sobre el trazo de antiguos caminos que conectaban la ciudad con haciendas, fábricas y fraccionamientos, se convirtieron en ejes de estructuración del espacio suburbano primero y metropolitano después (Melé, 1994).

El fraccionamiento de La Paz fue el primero en romper con la cuadrícula original en 1947, en el cerro de San Juan al poniente y poco después le siguieron otros similares como Rincón del Bosque y La Calera (Montero, 2006). Por su parte, el primer fraccionamiento en romper la continuidad fue el de San Manuel (1953) al colocar en el mercado más de 3000 grandes lotes al sur de la ciudad, encareciendo las parcelas cercanas. Otros fraccionamientos exclusivos se asentaron también fuera del centro, como símbolo de un estatus social elevado, de acuerdo con tipologías y estilos arquitectónicos importados (Montero, 2002a). Simultáneamente, se formaron asentamientos irregulares en terrenos ejidales en distintas direcciones de la periferia. ${ }^{6}$

El espacio urbano se polarizó aún más. Muy pronto, pueblos cercanos, como Xochimehuacán y La Libertad, quedaron conurbados a la ciudad que veía cómo se duplicaba su población en apenas 20 años, alcanzando unos 297000 habitantes en 1960 y su área urbana llegando a 2500 hectáreas (Anexo). Esa expansión sin control y la desarticulación de la ciudad habían afectado la movilidad y la dotación de servicios y equipamiento (Vélez, 2007).

Para atender la demanda habitacional de empleados públicos el gobierno estatal instrumentó el Programa de Cooperación para la Construcción de Casas de Costo Mínimo (1957), pero apenas logró concretar dos unidades de 200 y 300 casas cada una (Montero, 2002a).

Por su parte, para regular las nuevas áreas urbanas se requirieron numerosos estudios a cargo de comisiones ciudadanas que incluían al sector privado, como el Plan de Mejoramiento Urbano de 1959 que indicaba las zonas urbanizables, la ubicación para servicios públicos y equipamiento urbano, así como un acertado esquema vial, que articulaba una zona industrial y de habitación popular al norte de la ciudad con el resto del área urbana. Paradójicamente, ese primer instrumento de planeación de la expansión prevista no llegó a implementarse.

${ }^{6}$ Al norponiente, las colonias Aquiles Serdán, Francisco Villa Caleras, Agrícola Ignacio Zaragoza; al sur, Guadalupe Hidalgo, y al poniente, Reforma Sur, Santa Cruz y Buena Vista. 


\section{CONFORMACIÓN METROPOLITANA Y CONSOLIDACIÓN DE LA PROMOCIÓN INMOBILIARIA, 1960 A 1974}

En estricto sentido, no existe una relación causal entre conformación metropolitana y la promoción inmobiliaria. Pero en el caso de la ciudad de Puebla, las políticas adoptadas ante la emergencia urbana ofrecieron a las empresas de bienes inmuebles condiciones favorables para su desarrollo.

En esta etapa, la urbanización se incrementó, empeorando las condiciones habitacionales para los sectores más bajos. Aunque prosperaron el sector de la construcción y el financiero mediante programas con recursos públicos y privados - apoyados por créditos internacionales-, estos se dirigieron a formar un sector social más solvente y promover el acceso a la vivienda por la vía de la adquisición, lo que generó ganancias adicionales al capital privado.

Fueron varios los factores externos y locales que coincidieron para crear el clima propicio. Simplificando esa convergencia de intereses, fueron tres los procesos que dieron impulso a la dimensión metropolitana de la ciudad: la descentralización nacional de la industria, la renovación del centro histórico y una mayor complejidad del mercado de suelo y la vivienda.

\section{La descentralización industrial}

La economía poblana estuvo dominada históricamente por la fabricación de textiles y cerámica, pero a partir de los años sesenta, se diversificó de tajo. Como parte de una tendencia mundial hacia la relocalización industrial, el gobierno federal ubicó a Puebla como un receptor importante de la industria ubicada en la Ciudad de México. Esa redistribución fue la que más encauzó la ciudad hacia una escala metropolitana.

La industria poblana recibió empresas nacionales y transnacionales del sector automotriz, metalúrgico y alimenticio. Se otorgaron incentivos fiscales a empresas industriales principalmente extranjeras, dispuestas a establecerse en las inmediaciones de Puebla (Arellanes, Kunz y Valverde, 2003). Para ello, se decretó el Programa para la Promoción de Conjuntos, Parques, Ciudades Industriales y Centros Comerciales, aunque las obras de infraestructura regional necesarias para reforzar su estratégica localización se realizaron antes de su promulgación. En 1962 se construyeron una red de energía eléctrica y la 
autopista México-Puebla. Se instalaron entonces, la ensambladora de autos Volkswagen en Cuautlancingo (1965) e Hylsa en Xoxtla (1967), ambas sobre propiedades ejidales (4 $760 \mathrm{ha}$ ) y privadas (7 411 ha) (López, 1997).

¿Cómo influyó este proceso en la estructura metropolitana de la ciudad? Definitivamente no de la mejor forma. En primer lugar, muchos de los fraccionamientos y parques industriales se ubicaron en sitios cada vez más alejados del municipio central. Segundo, por el efecto determinante que trajo consigo la nueva autopista. El trazo designado en el Programa de 1959, simplemente se ignoró al elegir el paso de la nueva vía. En tercer lugar, la nueva concentración industrial creó una demanda general de suelo y vivienda, así como de servicios, que desarticuló las zonas previstas para ello en el Plan de 1959. Los territorios afectados se vieron frente a una situación inédita que la planeación convencional no atina aún en resolver, aumentó la plusvalía regional y modificó el modo de vida tradicional, al expropiar y transformar extensas tierras de cultivo de larga data (Ávila, 2009; Bernal, Ramírez, Estrella, Pérez y Morett, 2010; Hernández et al., 2009) (véanse mapas 2 y 3 y Anexo). ${ }^{7}$

A pesar de que a fines de este periodo se sentaron las bases de reformas estructurales del marco legal y de planificación a nivel nacional y de las respuestas a los movimientos sociales que emanaron de ellas, sin un marco de planeación congruente, la industrialización inducida marcó de forma irreversible el patrón espacial de la aglomeración y se reflejó también en el centro de la ciudad.

\section{La refuncionalización del centro}

En la literatura especializada se reconoce la primacía de las áreas centrales de una ciudad para alojar actividades comerciales y de servicio (Alonso, 1964; Hall, 1981; Robson, 1988).

En el caso de Puebla había que remontar el abandono y deterioro que padecía su centro histórico para cumplir cabalmente ese papel. A pesar de la inversión estatal realizada, con una legislación urbana actualizada y una

${ }^{7}$ En 1962 se suprimió el estatus municipal de cinco municipios aledaños (San Jerónimo Caleras, San Felipe Hueyotlipan, San Miguel Canoa, La Resurrección, al norte y San Francisco Totimehuacán, al sur) que habían quedado atrapados conforme se expandía la ciudad y se le subordinó al nivel operativo de Junta Auxiliar (PDUCP, 1991). 


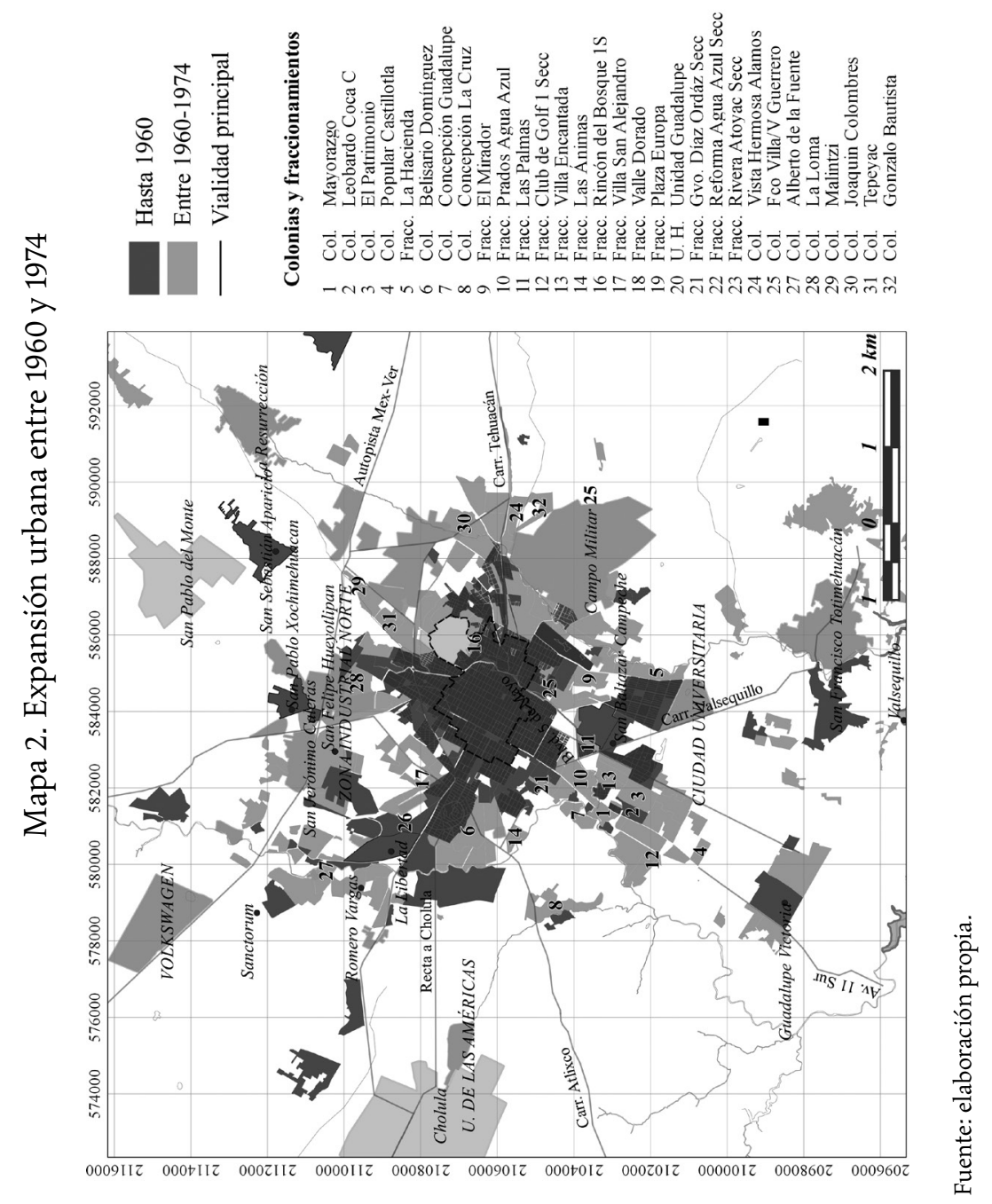



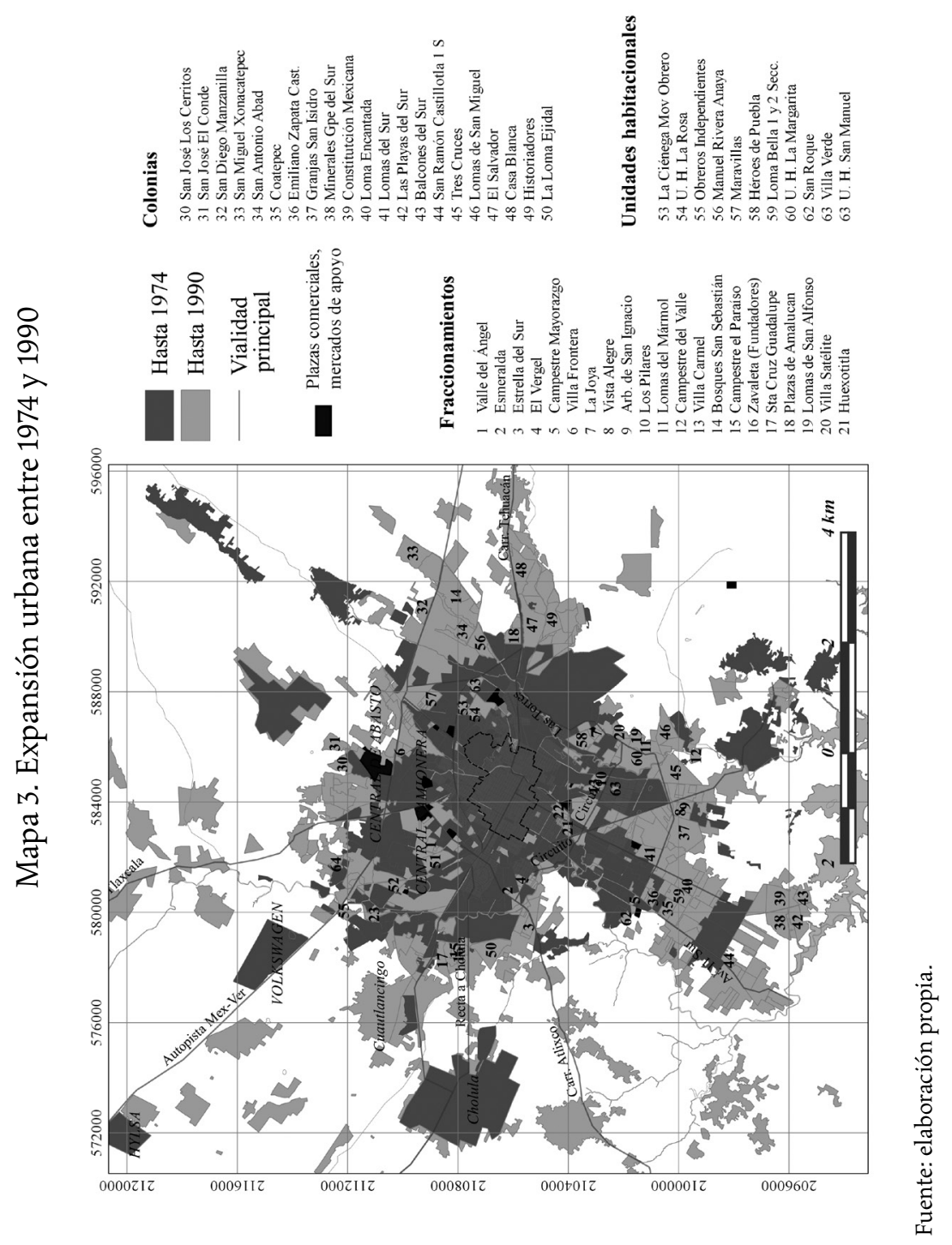
industria reconvertida, el centro mostraba un abandono inquietante y en general, se padecía un elevado déficit de servicios, infraestructura y vivienda (Méndez, 1989). Así que para recuperar la circulación de vehículos se decidió en 1963 abovedar el río San Francisco y construir sobre su antiguo cauce el Boulevard H. de 5 de Mayo. Una decisión similar se aplicó indiscriminadamente en la ciudad de México (González, Hernández, Perló y Zamora, 2010).

Otras dos intervenciones, ahora en servicios de educación superior, fueron la instalación de la Universidad de las Américas en 1967 y de Ciudad Universitaria en 1968. Asentada la primera en San Andrés Cholula, propició la conexión con la ciudad cuando se amplió y acondicionó la Vía Quetzalcóatl o Recta a Cholula en 1976. La inversión privada que vino con ella hizo muy atractiva la zona para segmentos sociales medios y altos, como los ejecutivos recién llegados de las empresas transnacionales que encontraron ahí un buen lugar para residir (Vázquez, 2007). En el caso de la Ciudad Universitaria la conexión con el centro la proporcionó el Boulevard Camacho Espíritu que, de paso, canalizó la urbanización hacia San Francisco Totimehuacán mediante conjuntos habitacionales como La Hacienda que aceleraron su conurbación con Puebla (Montero, 2002a).

\section{Configuración del mercado de suelo y vivienda}

La industrialización importada y la refuncionalización del centro desataron la intensa edificación de fraccionamientos en la ciudad. La entrada de programas de vivienda avanzados y la incorporación ilegal al mercado urbano de tierras ejidales, brindaron al capital financiero e inmobiliario una base excepcional para su ascenso.

Hasta entonces, los promotores que se habían limitado a la compra y adecuación de suelo para vivienda dejando la edificación al propietario y la comercialización a otras empresas, dominarían esos tres campos, condición necesaria para la creación de un mercado inmobiliario capitalista propiamente dicho (Jaramillo, 2009; Schteingart, 1989; Topalov, 1974, 1979). El negocio inmobiliario se nutrió de las aspiraciones de las nuevas clases medias y altas por poseer una vivienda propia en fraccionamientos exclusivos. A mediados de los setenta el fraccionador-promotor era ya el agente dominante, y su actividad un gran negocio especulativo (Vélez, 2007). 
En sólo catorce años, entre 1960 y 1974 se registraron formalmente 85 lotificaciones más, en 63 de ellas se vendieron unos 34000 predios individuales en 1400 hectáreas (Melé, 1994; Vélez, 2007). El área urbana se duplicó entre 1960 y 1974 para rebasar las 5600 hectáreas con una tasa demográfica de $6 \%$, la más alta de todo el siglo xx (mapa 2 y Anexo).

Al mismo tiempo, los incipientes institutos promotores de vivienda, instrumentados a nivel nacional desde mediados de los sesenta, asumieron la producción de vivienda social como una tarea gubernamental. Bajo este esquema el gobierno estatal aprobó la construcción de unidades populares que apoyaban al capital inmobiliario y a solicitantes de ingresos bajos. ${ }^{8}$

Además de liberar fuerza de trabajo para las ciudades, el abandono de la agricultura en la política económica minó el interés en conservar la tierra como medio de trabajo. En consecuencia, ampliar las zonas urbanas ejidales se convirtió en una forma de construir vivienda a bajo costo. La ocupación irregular del suelo, aunque no formó parte de las operaciones inmobiliarias, introdujo tierra adicional al mercado. Desde fines de los sesenta se anexaron considerables extensiones de tierra ejidal y comunal como veremos más adelante. Después de un corto periodo de informalidad estos asentamientos, conocidos como colonias populares, pasaron al mercado formal.

La regularización del suelo constituiría un medio de control de la oligarquía, generalmente ligada al PRI; la estabilización habitacional de una gran parte de la población, y la dinamización del mercado de bienes raíces, fuente de nueva acumulación de capital (Castells, 1977).

Se desplegó, además, otro periodo de intensa actividad constructiva de fraccionamientos formales medios y altos al poniente, hacia el sur y al norte de la ciudad. ${ }^{9}$ Otras lotificaciones irregulares en corredor se extendieron sobre la carretera federal a Tehuacán, cada vez más lejos de los servicios de la ciudad interior. ${ }^{10} \mathrm{Al}$ despuntar los años setenta y a menos de diez años de la llegada

${ }^{8}$ En el suroriente se construyó la Unidad Guadalupe; al sur las unidades Alpha Dos, Gustavo Díaz Ordaz, Reforma Agua Azul y Rivera del Atoyac (Montero, 2002b).

${ }^{9} \mathrm{Al}$ poniente, el conjunto Belisario Domínguez, Concepción Guadalupe y Concepción La Cruz; hacia el sur se edificaron El Mirador, Prados Agua Azul, Las Palmas, Club de Golf, Villa Encantada, Las Ánimas, San José Vista Hermosa (ejidal); al norte, Rincón del Bosque, Villa San Alejandro, Valle Dorado.

${ }^{10}$ Vista Hermosa Álamos, Francisco Villa Caleras, Clotilde Torres, Alberto de la Fuente, La Loma, Malintzi, Joaquín Colombres, Tepeyac, Gonzalo Bautista. 
de la industria a la zona, cinco municipios colindantes con Puebla estaban ya funcionalmente ligados a la ciudad (Flores, 1993). ${ }^{11}$

\section{DOMINIO DEL SECTOR INMOBILIARIO EN LA CIUDAD DE 1974 A 1990}

En Puebla, al agotado modelo del Estado benefactor lo reemplazó una estructura mixta. En la práctica, aglutinó a un sector inmobiliario privado cada vez más fuerte con organismos públicos de vivienda asociados al sector privado, ambos con un escenario marcado por invasiones de tierras ya sin ningún viso de cobertura legal. La ampliación del mercado de vivienda, promovida por el Estado, permitió el fortalecimiento y movilidad del mercado capitalista de la construcción.

El gobierno municipal respondió a las nuevas condiciones desplazando la promoción pública mientras la ciudad duplicaba su extensión y conformaba un contorno intermedio. Factor crucial para dotar de coherencia metropolitana a cualquier ciudad. Esta posibilidad se frustró por estar más encauzada por una lógica de mercado que por una política urbana con sentido social.

\section{Una planificación urbana formal rebasada por la urbanización real}

Ante el desbordamiento de los controles normativos, en 1974 el ejecutivo estatal actualizó la antigua Ley de Fraccionamientos de 1940 en un intento por restringir el mercado de suelo formal y retomar la facultad para autorizar fraccionamientos.

Se trató de una modificación formal. Los fraccionamientos se tipificaron como residenciales, medios y populares según el tamaño de los lotes, pero sin fijar densidades específicas de ocupación del suelo a cada uno de ellos; tampoco se determinó alguna zonificación de usos o su compatibilidad funcional con el entorno inmediato (Melé, 1994). El sistema inmobiliario respondió de forma reactiva, asociándose con los propietarios de terrenos y llegaron

${ }^{11}$ San Andrés Cholula, San Pedro Cholula, Amozoc, Cuautlancingo, San Pablo del Monte (Tlaxcala). 
a ejecutar obras urbanas para apropiarse directamente de la revalorización de los terrenos en donde invertían.

Con el mercado de suelo bajo su dominio y con un amplio control de las fases de promoción se conformó un capital inmobiliario y financiero según el esquema teórico previsto por Topalov (1979) y más adelante por Jaramillo (2009).

\section{Planificación estatal y política nacional de vivienda}

Por otro lado, en este periodo entraron en operación en Puebla los organismos nacionales de vivienda (Infonavit, Fovissste, Fonhapo, shF), ${ }^{12}$ que respondían a la nueva demanda de trabajadores industriales y prestaban un control social de los mismos. Estos organismos se crearon para financiar la construcción -ejecutada por empresas privadas-, la adquisición o el mejoramiento de las viviendas, con recursos propios y designando a quienes podían ser sujetos de crédito. Bajo este esquema se construyeron numerosas unidades habitacionales, pero también se reestructuró la burocracia política que administra los trámites para regular la urbanización (véase cuadro 1).

Entre 1974 y 1990, el Instituto del Fondo Nacional de Vivienda para los Trabajadores (InFonAvit) dirigido a los trabajadores del sector privado, construyó unas 31000 viviendas en 28 unidades habitacionales, la mayoría en la periferia norte, ${ }^{13} 14 \%$ del parque habitacional en ese entonces y $39 \%$ de la vivienda construida en el municipio central. La gestión para distribuir las viviendas se otorgó a los sindicatos del sistema corporativo del PRI. La CTM y la Froc obtuvieron más de 6000 cada una, la CROC y CROM más de 1000 viviendas y otras 2500 fueron asignadas al sindicato de Volkswagen, otrora radical y de izquierda (Melé, 1994). Como la aprobación de esos financiamientos estaba a cargo del gobierno federal, con frecuencia se incumplía con reglamentos locales y guardaban muy poca relación con la planeación municipal y estatal, llegando incluso a ocupar zonas de reserva agrícola o naturales (mapa 3).

${ }^{12}$ Para profundizar en sus funciones y evolución véase Bredenoord y Cabrera (2014).

${ }^{13}$ Unidades La Ciénega-Movimiento Obrero, La Rosa, Obreros Independientes (vw), Fidel Velázquez, Manuel Rivera Anaya, Maravillas y otras al sur como Héroes de Puebla, Loma Bella y La Margarita. 


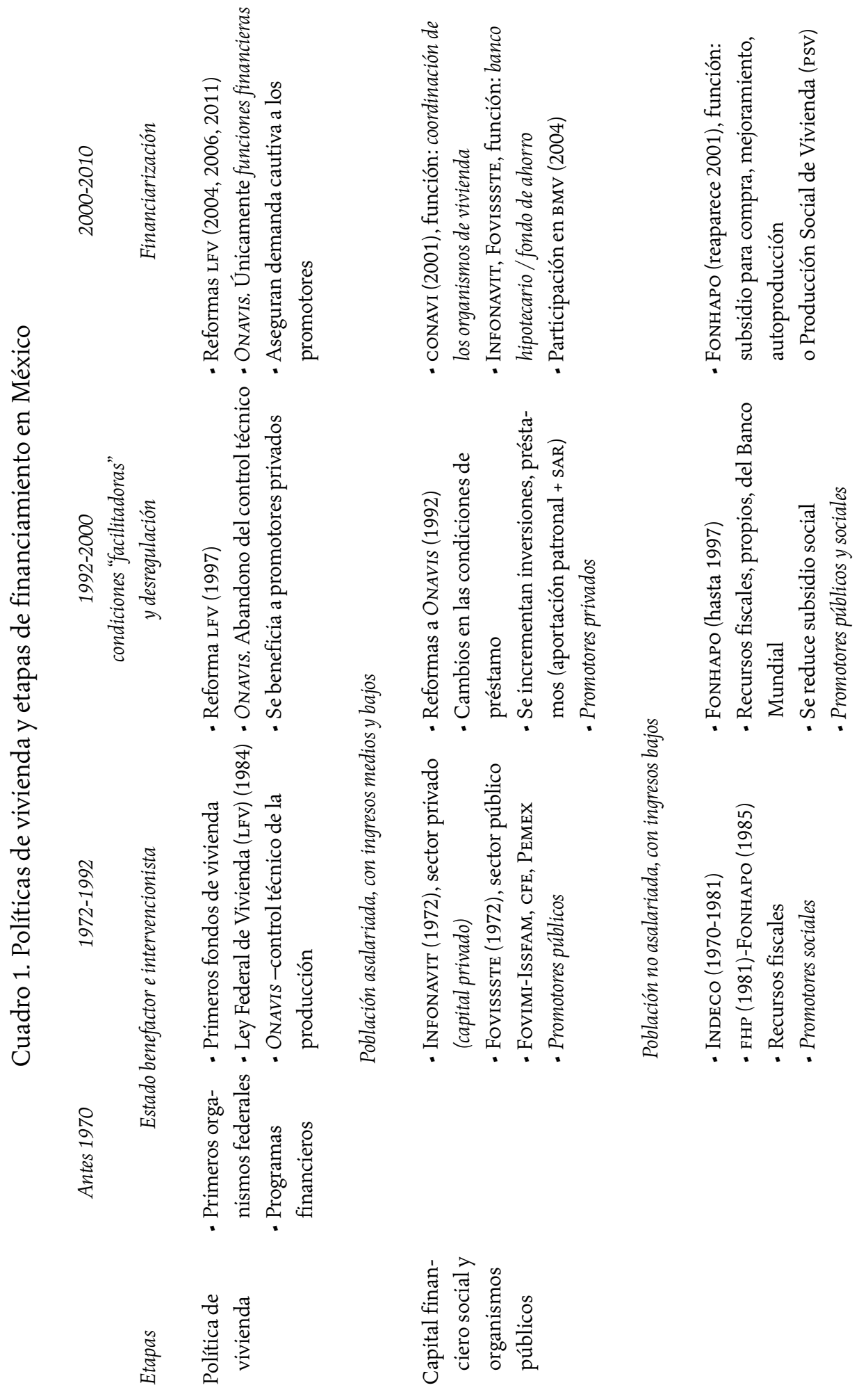



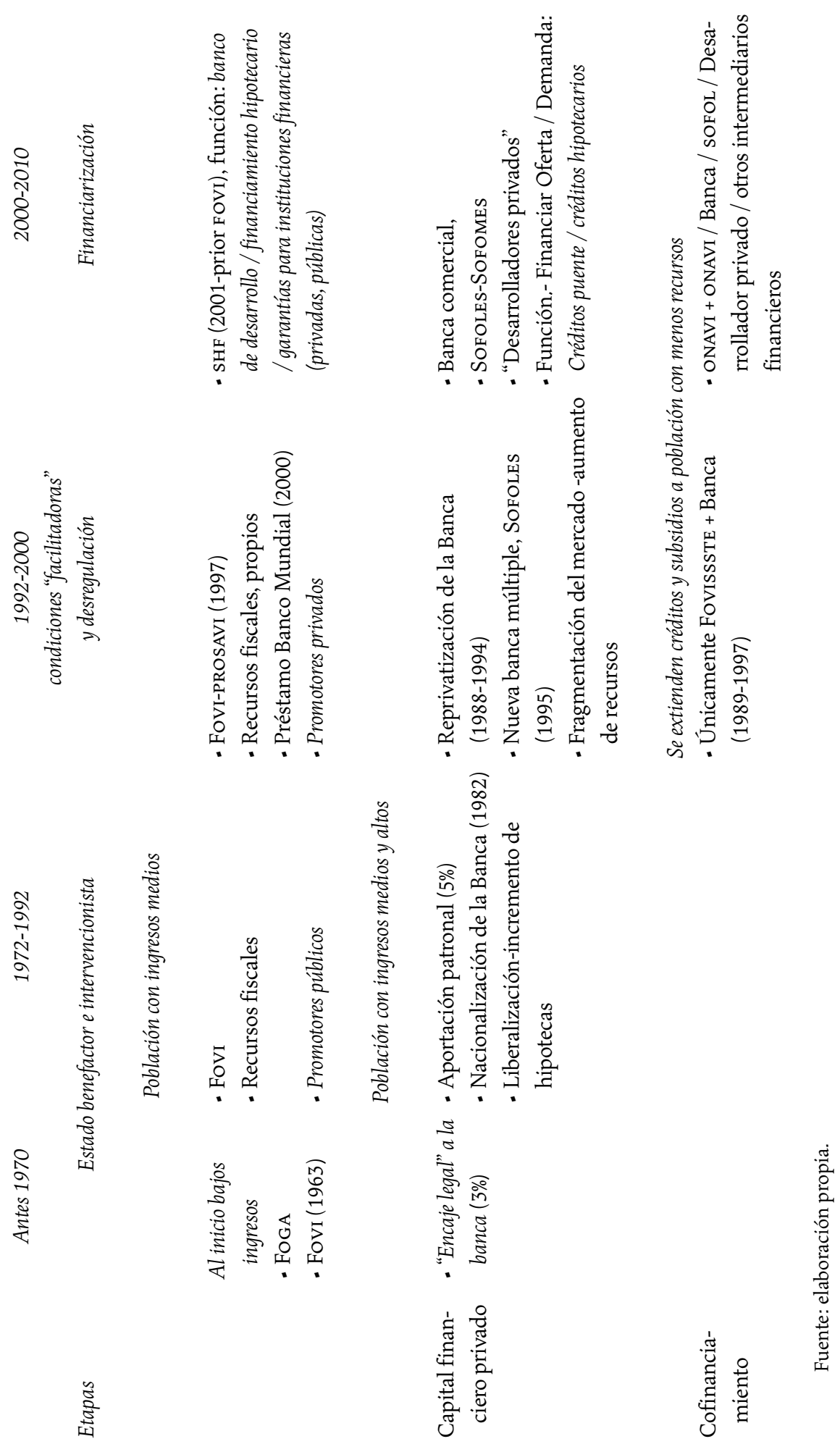
Otros organismos tuvieron una menor participación. Entre 1979 y 1990 el Fovissste construyó 1619 departamentos en cuatro condominios al norte y sur de la ciudad..$^{14}$ El INDECo realizó entre 1978 y 1982 algunas operaciones de regularización y creación de fraccionamientos populares, construyó un conjunto habitacional al noroeste y una colonia de vivienda progresiva en el sur. ${ }^{15}$ Por su parte, el gobierno del estado fundó su propia inmobiliaria en 1982 para alojar programas de vivienda a través de INDECO, en coordinación con FonHAPO y llegó a comercializar un total de 1664 viviendas al sur ${ }^{16}$ (Melé, 1994). A pesar de estar dirigido al sector popular, el FonHAPo carecía de facultades para apoyar programas de autoconstrucción o de vivienda progresiva. Los organismos estatales de vivienda intervinieron con poca incidencia como el Comité de Planeación para el Desarrollo del Estado de Puebla (Coplade) en 1981 o tres años después el Instituto de Vivienda de los Trabajadores del Estado de Puebla (VITEP) a cargo de la Secretaría de Asentamientos Humanos y Obras Públicas del Estado (SAHoper).

\section{El sector inmobiliario amplía sus actividades durante las crisis}

La devaluación de 1982 agravó la capacidad de ahorro de las clases medias y su acceso al financiamiento privado bancario. Con el aumento de las tasas de interés, de los precios del suelo y sin directivas claras de regulación, las inmobiliarias saturaron el mercado de suelo y a pesar de que las condiciones de operación les garantizaba una inversión rentable, sus destinatarios potenciales ya no las podían pagar y hubo entonces menos solicitudes legales para edificar (López, 1997; Melé, 1994). Una vez desatada la crisis, las empresas de bienes raíces no redujeron su actividad, por el contrario, ocuparon importantes espacios discontinuos a lo largo de vialidades primarias que reforzaron su papel como ejes radiales a partir del centro (López, 1997).

Hasta entonces la producción de fraccionamientos se había dirigido principalmente al sur hacia Valsequillo; al surponiente, a orillas de las vías a Atlixco y Cholula; y al norte, hacia Tlaxcala, pero se extendió su producción

${ }^{14}$ La U. H. San Manuel en 1979, la U. H. San Roque en 1982, al sur y las U. H. Villa Verde I y II y La María, al norte.

${ }^{15}$ Regularizó Castillotla y Zapata, y realizó vivienda progresiva en Coatepec.

${ }^{16}$ Destaca el caso de la colonia Balcones del Sur, localizada en los márgenes del lago de Valsequillo. 
en todas direcciones de la ciudad. ${ }^{17}$ Mientras, en este periodo los municipios Cuautlancingo y Amozoc se conurbaron al municipio central.

Una nueva generación de fraccionamientos hizo su aparición. Aunque en los años sesenta había ya algunos vecindarios cerrados como la Plaza Europa en la colonia Bella Vista y otros al norponiente, a partir de los ochenta estos se multiplicaron, ocupando vacíos urbanos y otros en los márgenes de la periferia. ${ }^{18}$ Para la población solvente, el diseño de espacios privados, exclusivos y seguros representaba un sitio ideal para vivir. Otros fraccionamientos antes abiertos, fueron cercados siguiendo esa práctica (Milián y Guenet, 2006) (mapa 3). En lugar de aplicar la normatividad vigente a esos asentamientos dispersos e inconexos, la actitud permisiva de las autoridades contribuyó a incrementar la fragmentación del tejido urbano, a complicar la movilidad y a intensificar la diferenciación socioespacial.

Por su parte, la magnitud de tierra incorporada al mercado a través de la ocupación irregular explica el interés por regularizarla, a pesar de sus magros resultados. Desde 1974, la regularización a cargo de la Comisión para la Regularización de la Tenencia de la Tierra (CORETT), fue lenta y muy pocos los casos atendidos. Otra iniciativa gubernamental intentó dar cierta coherencia a la expansión mediante un proyecto de Reserva Territorial, entre 1984 y 1987, pero tuvo también pobres resultados. De los dos ejidos seleccionados, ninguno prosperó por la especulación desatada, o bien, porque los ejidatarios se opusieron a la expropiación. Uno de ellos terminó siendo zona de asentamientos populares mientras que el otro se fraccionó ilegalmente ${ }^{19}$ (López, 1997; Melé, 1994).

\section{Efectos territoriales de la expansión}

La formación de un contorno intermedio, representativo de los cambios urbanos que experimenta una ciudad en expansión, desde el punto de vista

${ }^{17}$ Fraccionamientos El Vergel, Campestre Mayorazgo, Villa Frontera, La Joya, Los Pilares, Villa Carmel, Bosques de San Sebastián, Plazas Amalucan.

${ }^{18}$ Como Valle del Ángel, Esmeralda, Estrellas del Sur, Vista Alegre, Arboledas de San Ignacio, Lomas del Mármol, Campestre del Valle, Campestre el Paraíso, Zavaleta, Santa Cruz Guadalupe, Lomas de San Alfonso, Villa Satélite.

${ }_{19}$ Al noreste el ejido La Resurrección (255 ha) y al sur, San Baltazar Campeche (159 ha), respectivamente. 
teórico y en la literatura especializada se considera como indicativo de una transición urbana. Ese contorno intermedio se forma mientras nuevas áreas urbanas se alejan más y más del centro, en parte debido a una descentralización económica y de población hacia zonas cercanas al centro, y en parte porque para entonces esas áreas han alcanzado un nivel de consolidación que aún no tienen las periferias más recientes, pero tampoco son parte del centro propiamente dicho (Gorsem, 1981).

En nuestro caso, las cifras sobre la superficie urbanizada entre 1970 y 1990 son muy discordantes entre sí, pero por la magnitud que alcanzó, corresponde a la fase intermedia del enfoque teórico señalado. De acuerdo con distintas fuentes, la ciudad tenía una extensión de 6000 hectáreas a mediados de los setenta; 6800 a fines de la década y 12800 en 1990. Además, se volvió a rebasar el límite municipal que había sido modificado unos años atrás, precisamente para controlar la expansión. Para el año 2000 la discrepancia es mucho mayor y oscila entre 22600 y 27000 hectáreas $^{20}$ (véase Anexo).

En los ochenta salieron del centro mercados de apoyo y se creó la Central de Abastos, como parte del Plan de Desconcentración Comercial de 1980. Se crearon nuevas universidades, plazas comerciales y por el sector público, escuelas, hospitales y otros servicios como la central de autobuses foráneos (CAPU). El objetivo de estas acciones era descongestionar las áreas centrales y no la restructuración metropolitana. Según Germain y Pólese (1996), la ubicación de los nuevos equipamientos en la periferia respondía a la movilidad generada por sectores de ingresos medios y altos, a quienes se dirigían las obras habitacionales y de servicios (mapa 3).

Este punto de inflexión se caracteriza por el despoblamiento central y tasas de crecimiento social más altas en los municipios intermedios. En efecto, la tasa del municipio central cayó de 6\%, entre 1960 y 1970, a 4.6 y $2.3 \%$ en 1980 y 1990, respectivamente (INEGI, varios años); correlativamente las tasas en municipios de reciente metropolización como San Andrés y San Pedro Cholula fueron de 3 y $4 \%$, respectivamente, y de entre 4 y $5 \%$ en Amozoc y Cuautlancingo.

Al final del periodo, el abatimiento de la promoción pública se acompañó del afianzamiento operativo de la promoción privada; y la producción

${ }^{20}$ Véase PducP (1991) para mediados de los 70; PMdusP (2005) para los 90; para el 2000 (Balderas, Mayorga y Méndez, s.f.) para la cifra de 22600 y Sedesol, ConApo, INEgi (2007) para la de 27000. 
por encargo perdía fuerza ante el nuevo sistema financiero. En el otro extremo social, la autoconstrucción resultó afectada por el encarecimiento generalizado del suelo e insumos de construcción, lo que empeoró la penuria habitacional de sectores ya empobrecidos.

\section{PREDOMINIO DEL SECTOR FINANCIERO Y DE LA PROMOCIÓN INMOBILIARIA PRIVADA, 1990-2010}

Este periodo marcó un momento de inflexión que redefinió los procesos de incorporación masiva de tierras a la urbanización, en especial del suelo social, así como en la reorientación de la política nacional en materia de vivienda, en el marco global de reestructuración económica del país de desregularización, privatización, apertura comercial, y más adelante de financiarización. ${ }^{21}$

\section{Intervenir el suelo social para proyectos inmobiliarios}

En este periodo se promulgaron numerosos instrumentos de planeación ${ }^{22}$ para abordar problemas urbanos particulares mediante la desincorporación de funciones estatales y redefinición de roles de los agentes involucrados en la urbanización. Ello se hizo, sin embargo, sin una perspectiva metropolitana y gracias a algunas de esas medidas los promotores inmobiliarios pudieron ocupar tierra social desde la lógica del mercado. Son los casos del Plan de Desarrollo Regional Angelópolis de 1993, que incluyó el proyecto de las reservas territoriales Atlixcáyotl y Quetzalcóatl; la reforma a la Ley de Fraccionamientos en 1997 y la publicación de la Ley de Fraccionamientos y Acciones Urbanísticas del Estado Libre y Soberano de Puebla en 2004.

Estas modificaciones al principal instrumento de intervención local en el mercado de suelo desperdiciaron la oportunidad de establecer mecanismos

${ }^{21}$ La relación entre el auge de la promoción inmobiliaria y estos procesos, merece una atención especial. Por su parte dicho auge se presenta en dos periodos, uno de condiciones "facilitadoras", de 1990 a 2000, acondicionamiento, reestructuración del capital financiero y establecimiento de nuevas condiciones de acceso al suelo; $y$ otra de "financiarización" que dio liquidez a la promoción inmobiliaria, de 2000 a 2010.

${ }^{22}$ Hubo planes de desarrollo urbano parciales, sectoriales, municipales, estatales y de ordenamiento. 
para evitar los efectos especulativos que indujeron las importantes reformas al suelo y a la vivienda, y las inversiones de estos años; tampoco fueron útiles para reordenar el área metropolitana, ni para recapturar los incrementos en los precios del suelo y redistribuir los recursos más equitativamente.

Las primeras obras realizadas en 1993 captaron cuantiosas inversiones federales y estatales para construir el acuaférico Nealtican-Puebla, el arco poniente-sur del anillo periférico y otros radiales y distribuidores viales, así como acciones de conservación y ordenamiento en el centro histórico. Es difícil entender que no se haya previsto la terciarización de la economía al dar prioridad a la dotación de servicios, construcción de zonas comerciales y residenciales, así como de diversas obras de saneamiento. El resultado fueron el despojo a ejidatarios, la expropiación de casonas en el centro histórico y la expulsión de antiguos pobladores de menores ingresos hacia la periferia (Salamanca, 2005; Vázquez, 2007).

El caso de las reservas Atlixcáyotl-Quetzalcóatl es quizás el más sorprendente. Fue aprobada en 1992 sobre tierra ejidal expropiada a precios muy bajos, con el objetivo explícito de atender la demanda de vivienda social. ${ }^{23}$ Esos objetivos se modificaron impunemente para convertir la reserva en un gran centro comercial para oficinas corporativas y vivienda para sectores de ingresos altos ${ }^{24}$ (véase mapa 4).

La planeación bajo una óptica social dejó de tener sentido. La sustituyó una forma de entrelazar lo público y lo privado que desde entonces caracteriza a la gestión urbana en Puebla.

${ }^{23}$ Los ejidos expropiados fueron el de San Andrés Cholula, San Bernardino Tlaxcalancingo, Santiago Momoxpan y La Trinidad Chiautenco.

${ }^{24}$ Las modificaciones a la Ley de Fraccionamientos de (1997) y a la Ley de Fraccionamientos y Acciones Urbanísticas del Estado Libre y Soberano de Puebla (2004), contemplaron la inclusión de figuras como Fraccionamiento Campestre y Club de Golf para este propósito. El Programa Subregional para el Desarrollo Urbano de los Municipios de Cuautlancingo, Puebla, San Andrés Cholula y San Pedro Cholula, de 1994, se modificó en diversas ocasiones, siendo la de mayor alcance en proporción de usos de suelo la de 2004, y finalmente se volvió a reformar en 2011. 


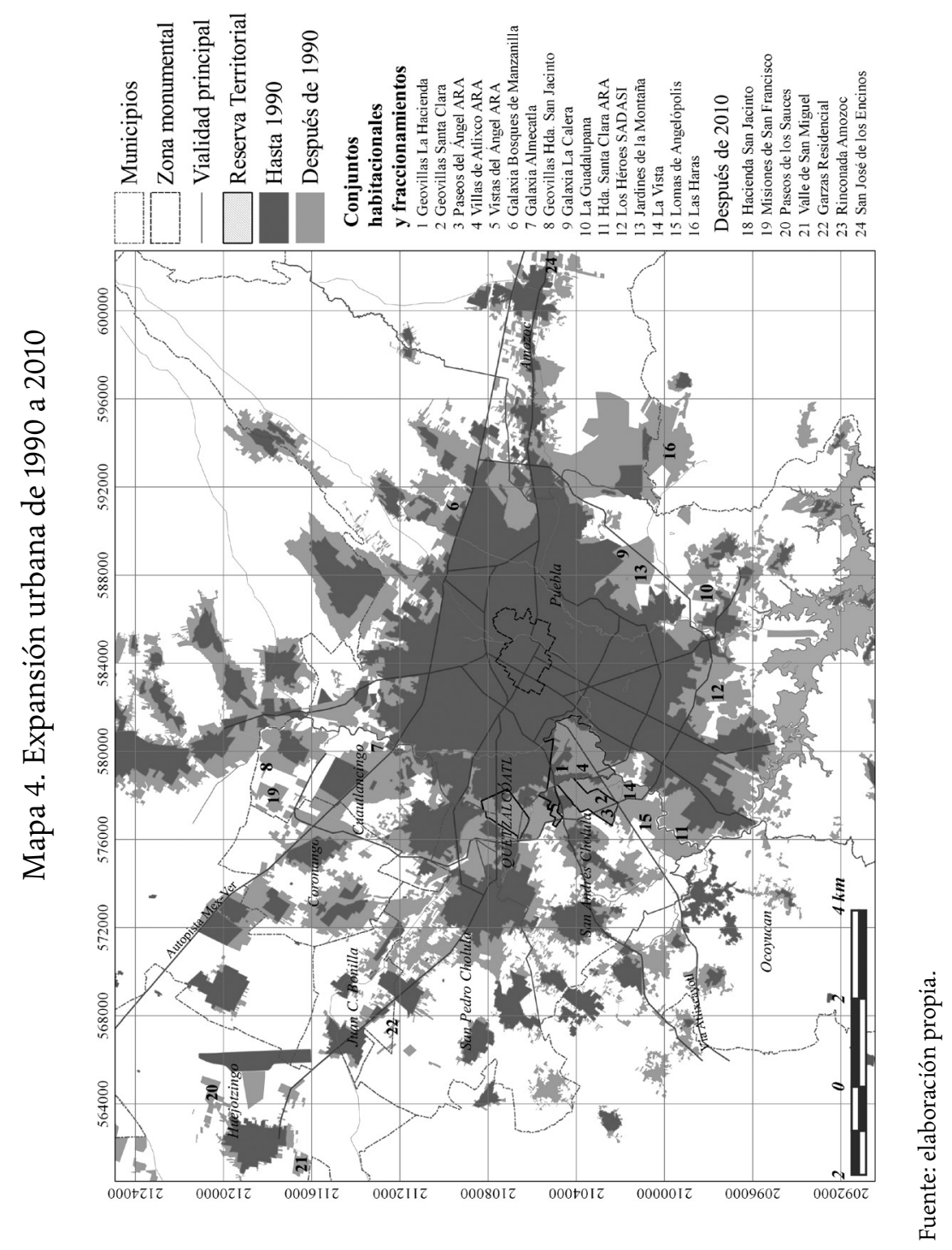




\section{Alinear iniciativas públicas y privadas en la gestión habitacional}

Lo expuesto hasta ahora corresponde a una política pública que opera en una economía de mercado. Este supuesto es una guía analítica práctica para el estudio de casos similares.

Primero, se gestionaron las iniciativas necesarias para intervenir suelo social bajo una cobertura legal, y se alinearon después elementos de un sistema, lo más diversificado posible, de políticas e instituciones de vivienda, públicas y privadas. Entre 1992 y 2004 se propusieron iniciativas de este tipo como parte del proceso de privatización y liberalización del suelo ejidal y comunal con las reformas a la legislación agraria del artículo 27 constitucional. El objetivo fue la compra directa de tierra social o su transferencia al mercado del suelo mediante el otorgamiento a los ejidatarios del dominio pleno sobre sus parcelas (Baitenmann, 2001; Cruz, 2001).

A inicios de los noventa, se desplegaron las condiciones que posibilitaron la expansión del sector inmobiliario, ${ }^{25}$ una vez que se detonó la crisis económica de 1994-1995, que llevó a reducir los recursos financieros privados a través de fondos bancarios, continuó la transferencia del sector público al privado.

La intervención federal entre 2000 y 2006 se proponía reconducir la política habitacional para abatir el rezago, pero en la práctica, concedió libertades y privilegios a los promotores, como una mayor disponibilidad de capital, en especial con la incursión de las principales organizaciones de vivienda en la Bolsa Mexicana de Valores, lo que diversificó también los esquemas de financiamiento. ${ }^{26}$ Asimismo, se facilitó el acceso al suelo, en especial a las grandes empresas que tuvieron un alto desempeño hasta su interrupción y desplome por la crisis de 2008.

Por ejemplo, las empresas promotoras siguieron levantando, en asociación con los organismos nacionales de vivienda, conjuntos habitacionales de

${ }^{25}$ Se puede citar entre ellas, la movilización de recursos internacionales, la privatización bancaria 1989-1990, la venta de bancos en 1991-1992, las reformas al artículo 115 constitucional para descentralizar algunas atribuciones urbanas, las modificaciones al INFonAvit y al FoVISSste en 1992-1993 o el Programa de Fomento y Desregulación de la Vivienda, 1993-1994; (puec-unam, 2013). En el Programa Sectorial de Vivienda 1995-2000 se impulsó la desregulación y descentralización de la producción habitacional.

${ }^{26}$ Principalmente InfonAvit, Fovissste, así como grandes empresas promotoras; hubo nuevos intermediarios financieros y combinación de recursos público-privado, público-público para ampliar los créditos para vivienda (PUEC-UNAM, 2013). 
diverso tipo tanto en la periferia como en espacios vacíos en el interior de la ciudad. El InfonaviT participó en más de 70\% de los casos entre 1990 y 2010, tanto en número de acciones de vivienda como en montos de inversión, seguido por la SHF y por el Fovissste (ConAVI, 2012) (véase cuadro 2).

La promoción masiva y estandarizada que instituyeron estos promotores transformó de tajo la morfología urbana de Puebla, en principio por su fragmentación y baja densidad.

Al terminar la década, los grandes promotores privados de vivienda a nivel nacional -GEO y ARA- construyeron conjuntos de vivienda social y media, que albergan en promedio entre 200 y 1500 unidades cada una, ${ }^{27}$ principalmente en la reserva Atlixcáyotl. Más tarde, otros consorcios nacionales -como Sadasi, Sare- también construyeron, al norte y sur de la ciudad, más de 25000 viviendas en conjuntos habitacionales cerrados, algunos de ellos de muy mala calidad, aprovechando la accesibilidad que les proporcionó el anillo periférico. ${ }^{28}$

Con empresas promotoras locales, diferenciadas en medianas y pequeñas, se facilitó la edificación de numerosos conjuntos pequeños -de menos de 500 viviendas- en áreas ya consolidadas y en espacios dispersos en la periferia. Los conjuntos se levantaban en donde había terrenos disponibles más baratos y no en función de lo previsto en los planes vigentes de desarrollo urbano. Quedaban cada vez más lejos del centro y aislados unos de otros (mapa 4).

Debido a las restricciones que el gobierno de la ciudad de Puebla comenzó a asignar, como una nueva carta urbana con definición de usos de suelo y densidades, después de 2010, los promotores construyeron conjuntos habitacionales de gran magnitud en municipios más separados de la conurbación, cuya legislación era más maleable. ${ }^{29}$ Otro caso reciente y poco estudiado de promoción inmobiliaria de muy baja densidad que ha trasformado la

${ }^{27}$ Geovillas La Hacienda, Santa Clara, Paseos del Ángel, Villas de Atlixco, Vistas del Ángel.

${ }^{28}$ Galaxia Bosques de Manzanilla, Galaxia Almecatla y Geovillas San Jacinto de 2000 viviendas cada una, al norte, y Galaxia La Calera y La Guadalupana de unas 3500 viviendas, y Jardines de la Montaña proyecto de 7000 viviendas al oriente y Hacienda Santa Clara de alrededor de 5000 y Los Héroes Puebla de cerca de 15000 al sur.

${ }^{29}$ Por ejemplo, en Cuautlancingo, al norte de la planta VW, se edificó Hacienda San Jacinto y Misiones de San Francisco por GEO -más de 10000 viviendas-, en Huejotzingo, Paseos de los Sauces de ARA y Valle de San Miguel de HOMEX - de 8000 y 5000 viviendas-, Las Garzas Residencial del grupo local IVI en J. C. Bonilla; Rinconada Amozoc o San José de los Encinos en Amozoc. 


\section{Cuadro 2. Financiamiento de vivienda por organismos públicos en el área metropolitana de Puebla. ${ }^{a}$ Acciones y montos ejercidos, 1990-2010}

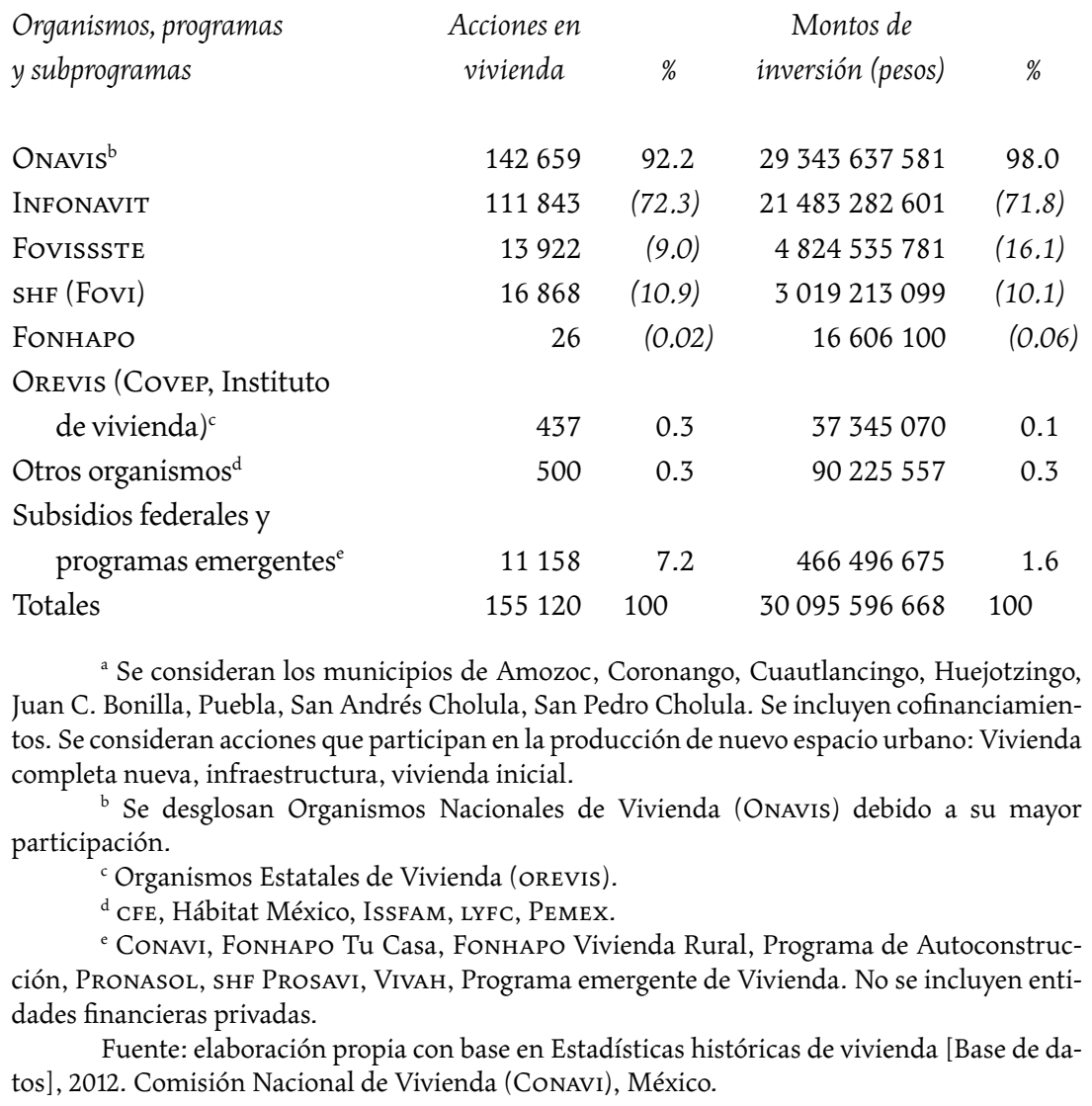

morfología urbana de Puebla son los macroproyectos residenciales de venta de lotes para construir después vivienda por encargo. ${ }^{30} \mathrm{La}$ superficie metropolitana en 2010 llegó a 41640 hectáreas, con más de 2000000 de habitantes;

${ }^{30}$ En San Andrés Cholula La Vista Country Club y Lomas de Angelópolis (que alcanza ahora al municipio de Ocoyucan), donde se ubican también torres de departamentos de lujo. 
en los municipios conurbados el parque de viviendas se duplicó en veinte años, aumentando en más de 267000 unidades (Anexo).

\section{LA ESPACIALIDAD RESULTANTE, UNA SÍNTESIS PROBABLE}

La secuencia de procesos descritos dejó una ciudad sobrepoblada y desorganizada pero bien articulada a la dinámica mundial mediante la industrialización importada, primero, y después a través de la financiarización del mercado de suelo y de la vivienda.

Esta lectura se sintetiza en dos rubros principales. Uno, sobre el modelo espacial que mejor explica esos cambios y, segundo, sobre los hitos principales de la política pública que los hizo posibles. El primero se refiere a la pertinencia del modelo clásico centro-periferia que permite interpretar, al mismo tiempo, la primacía de la centralidad y la expansión de una periferia que todavía no puede llamarse urbana pero ya no regresará a su origen rural. La consecuencia espacial derivada de ese engarce es el contorno intermedio que emerge como pieza clave para dotar de coherencia a la ciudad.

La ciudad de Puebla incluye un centro y un contorno intermedio, en los que se advierte ya el despoblamiento. Sobresalen la desarticulación incitada por la infraestructura regional al norte y la expansión conducida por el anillo periférico y la prolongación de las vialidades radiales en la periferia metropolitana. Ello ha inducido la formación de sectores que comparten una dinámica acelerada de crecimiento y una marcada desigualdad espacial, reflejo de las contradicciones apuntaladas por las políticas urbanas que no ha hecho más que garantizar el funcionamiento de los mecanismos de acumulación al capital inmobiliario.

Un tema que merece ser estudiado con profundidad es el esclarecimiento, desde un punto de vista económico, de la introducción de suelo social al funcionamiento del mercado, para articular el acervo logrado en el estudio de los aspectos sociales y políticos involucrados.

Lo aquí expuesto permite destacar dos factores que repercuten en la (des)estructuración de la ciudad. En primer lugar y siendo evidente la necesi-

Al oriente, entre Puebla y Amozoc, Las Haras Ciudad Ecológica dentro de una reserva ambiental que alberga la mayor diversidad de encinos en Latinoamérica. 


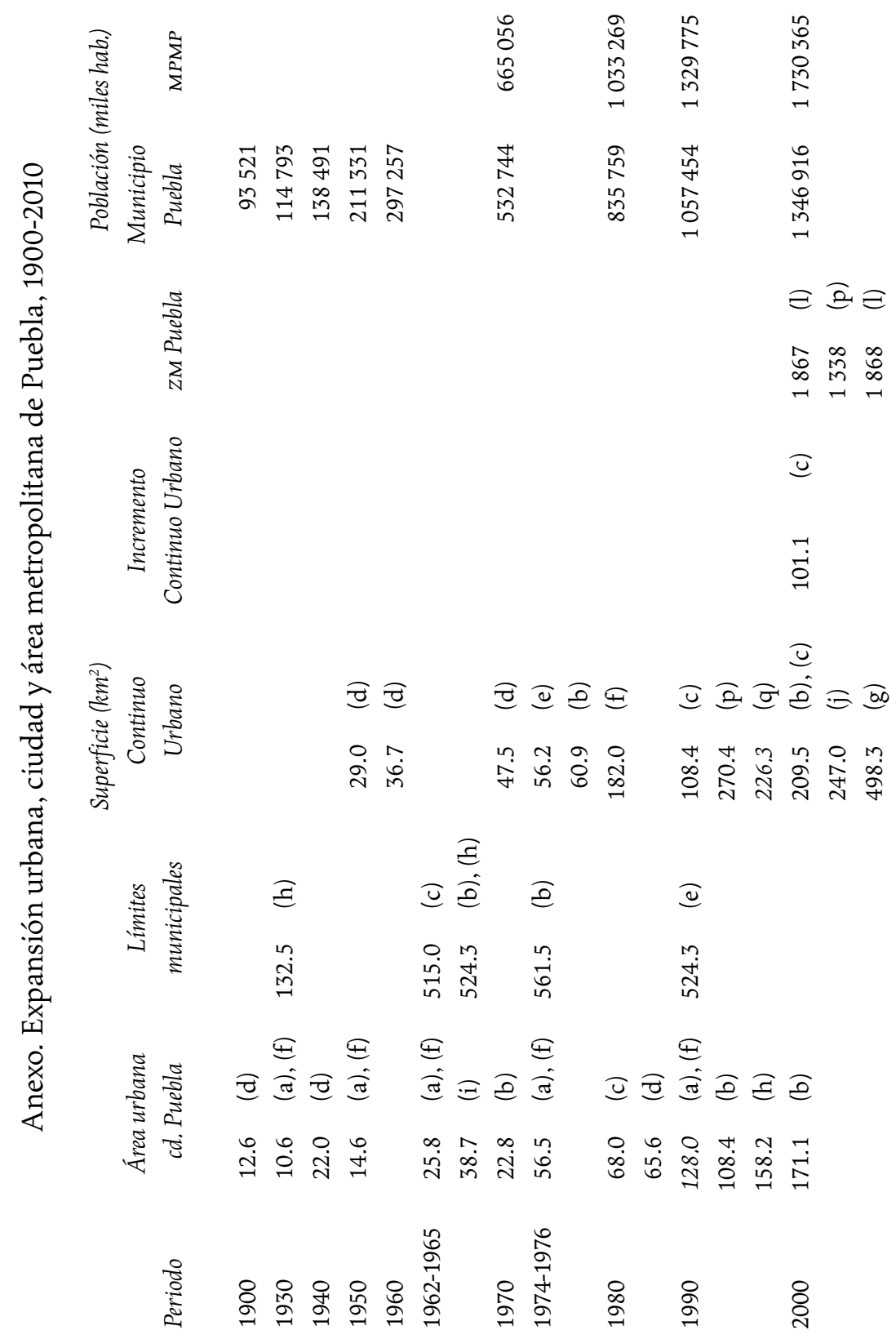




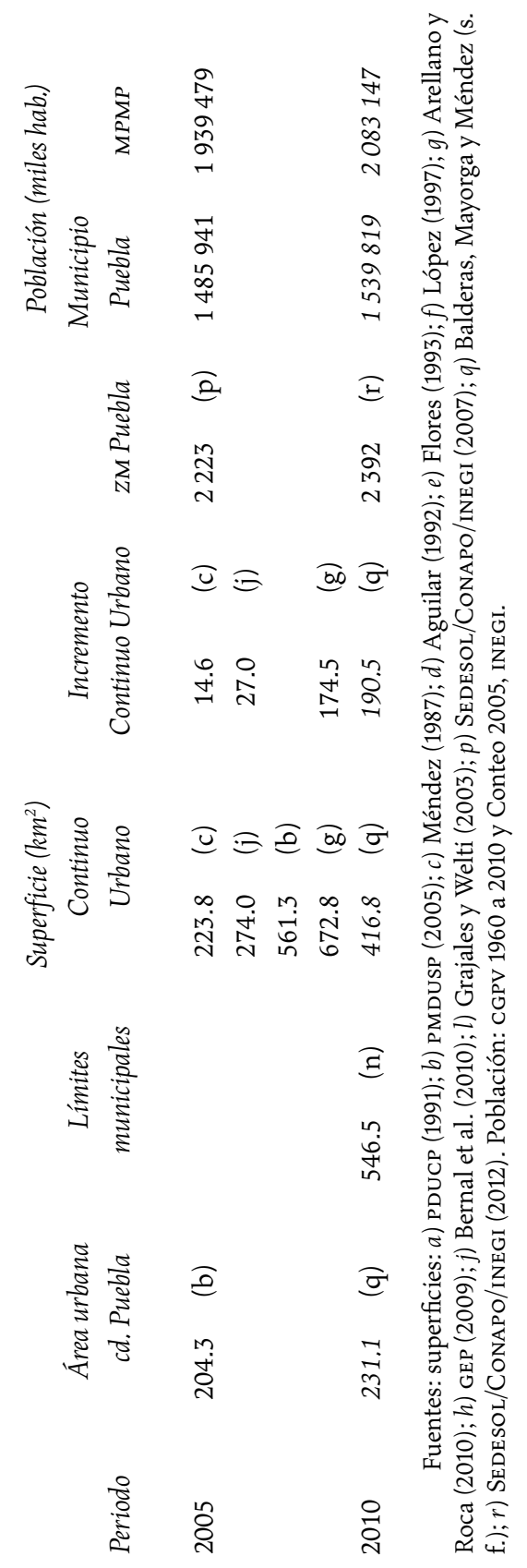


dad de alinear políticas nacionales con las estatales y municipales, en especial a lo relativo al suelo y a la vivienda, así como la imperiosa necesidad de una coordinación metropolitana, para tener buenos resultados. Los desajustes señalados pueden explicarse como un componente más del cambio estructural realizado desde una peculiar economía social a otra dominada por el mercado. En segundo término, es necesario que sea público y transparente el acceso a la información sobre suelo disponible y capacidad de pago de quienes intervienen a escala urbana, y que la legislación incluya instancias autónomas para el seguimiento y la rendición de cuentas sobre planes y programas urbanos fallidos. Aunque, se han realizado intentos de coordinación de las distintas instancias encargadas del suelo, del crecimiento urbano y de la producción de vivienda, como la creación de la SEDATU, en colaboración con CoNAvi, no alcanzan a reflejarse los resultados esperados en la configuración socioespacial del territorio.

Es necesario restituir la dimensión social de la ciudad, para alcanzar una ciudad mejor planificada.

\section{LISTA DE REFERENCIAS}

Aguilar, F. (1992). La expansión territorial de las ciudades de México. México: UAM-Xochimilco.

Alonso, W. (1964). Location and land use: toward a general theory of land rent. Cambridge, MA: Harvard University Press.

Arellanes, A., Kunz, I., Valverde C. (2003). Industria. En I. Kunz (coord.), Usos de suelo y territorios, tipos y lógicas de localización en la Ciudad de México (pp. 119-171). México: unAm/Plaza y Valdés Editores.

Arellano Ramos, B. y Roca Cladera, J. (2010). El urban sprawl, ¿un fenómeno de alcance planetario? Los ejemplos de México y España. ACE: Architecture, City and Environment, 4(12), 115-148. DoI: 10.5821/ace.v4i12.2489

Ávila, H. (2009). Periurbanización y espacios rurales en la periferia de las ciudades. Estudios Agrarios, 41, 93-123. Recuperado de http://www.pa.gob.mx/publica/ PA074101.html

Baitenmann, H. (2001). Las paradojas de las conquistas revolucionarias: municipio y reforma agraria en el México contemporáneo. Gestión y Política Pública, X(1), 103123. Recuperado de http://www.gestionypoliticapublica.cide.edu/?page_id=322 
Balderas, G., Mayorga, R. y Méndez (s. f.). Informe Técnico. Implicaciones climatológicas de la metropolización en el valle de Puebla. México: BUAP-Fondo Mixto-ConAсут/Gobierno del Estado de Puebla.

Barragán, J. I. (1994). 100 años de vivienda en México. Historia de la vivienda en una óptica económica y social. Nuevo León: Urbis Internacional.

Bernal, H., Ramírez, J., Estrella, N., Pérez, R., Morett, J. (2010). Importancia de los territorios rurales en el proceso de reestructuración territorial: el caso de la región metropolitana de la ciudad de Puebla. Economía, Sociedad y Territorio, 10(34), 625660. DoI: http://dx.doi.org/10.22136/est002010130

Borsdorf, A., Hidalgo, R., Sánchez, R. (2007). A new model of urban development in Latin America: the gated communities and fenced cities on the metropolitan areas of Santiago de Chile and Valparaíso. Cities, 24(5), 365-378. Dor: https://doi. org/10.1016/j.cities.2007.04.002

Bourdieu, P. (2001). Las estructuras sociales de la economía. Buenos Aires: Manantial.

Braudel, F. (1970). La historia y las ciencias sociales. España: Alianza Editorial.

Bredenoord, J. y Cabrera, L. (2014). Affordable housing for low-income groups in Mexico and urban housing challenges of today. En J. Bredenoord, P. van Lindert, P. Smets. Affordable housing in the urban global south: seeking sustainable solutions (pp. 223-240). Londres: Routledge/Earthscan.

Castells, M. (1974). La cuestión urbana. México: Siglo XXI.

Castells, M. (1977). Apuntes para un análisis de clase de la política urbana del Estado mexicano. Revista Mexicana de Sociología, 39(4), 1161-1191.

Conavi (2012). [Base de datos]. Financiamientos e inversiones ejercidas. Programa anual de financiamientos para vivienda, cierres definitivos por municipio (1990-2010). México: Conavi.

Contreras, C. A. (1984). La ciudad de Puebla en el siglo XIX: del estancamiento a la modernidad porfiriana. (Tesis inédita de maestría). Universidad Autónoma Metropolitana-Iztapalapa, México.

Cruz Rodríguez, M. S. (2001). Propiedad, poblamiento y periferia rural en la Zona Metropolitana de la Ciudad de México. México: UAM-Azcapotzalco/RNIU.

DIAU-BUAP (2010). [Base de datos, sig]. Registro histórico de localidades de Puebla. MéXiCO: DIAU-BUAP.

Feagin, J. (1979). The urban scene. Myths and realities. Nueva York: Random House.

Flores, S. (1993). Estructura territorial en la zona metropolitana de la ciudad de Puebla. México: UnAM.

García, B. (1988). La actividad inmobiliaria en la ciudad de Querétaro: 1960-1982. Cuadernos de Investigación Social, 17. México: UnAM. 
GEP (2009). Acuerdo conjunto de los ejecutivos de los estados de Puebla y Tlaxcala, por el que crea el "Consejo para el Desarrollo Metropolitano de Puebla-Tlaxcala". México: Gobierno del Estado de Puebla.

Germain, A. y Pòlese, M. (1996). La ecología humana de Puebla: ensayo de geografía residencial. En S. Pérez y M. Pòlese, Modelos de análisis y de planificación urbana. Estudios sobre la evolución de la ciudad de Puebla (pp. 63-88). Puebla: Plaza y Valdés/ BUAP.

González, A., Hernández, L., Perló, M. y Zamora, I. (2010). Rescate de ríos urbanos. Propuestas conceptuales y metodológicas para la restauración y rehabilitación de ríos. México: Coordinación de Humanidades-Puec-unAm.

Gormsen, E. (1981). Die Städte in Spanisch-Amerika. Ein zeit-räumliches Entwicklungsmodell der letzten hundert Jahre. Erdkunde, 35(4), 290-303.

Grajales, A. y Welti, C. (2003). Estructura y dinámica de la zona conurbada Puebla-Tlaxcala. Una visión comparativa, 1970-2000. México: Instituto de Ciencias Sociales y Humanidades-BUAP.

Hall, P. (1981). The inner city in context. Londres: Heinemann.

Harvey, D. (1985). The urbanization of capital. Baltimore, MB: John Hopins Press.

Harvey, D. (2007). Espacios del capital. Madrid: Ediciones Akal.

Hernández, J., et al (2009). Rurales y periurbanos: una aproximación al proceso de conformación de la periferia poblana. Papeles de Población, 15(61), 275-295.

INEgI (varios años). Censos de Población y Vivienda, viII (1960), Ix (1970), x (1980), XI (1990). México: Instituto Nacional de Estadística y Geografía.

Jaramillo, S. (2009). Hacia una teoría de la renta del suelo urbano, 2a. Edición. Bogotá, Colombia: Universidad de los Andes-Facultad de Economía.

Lefebvre, H, (2013). La producción del espacio. España: Capitan Swing.

Lojkine, J. (1979). El marxismo, el Estado y la cuestión urbana. México: Siglo XXI.

Lomelí, L. (2010). Historia breve de Puebla. México: El Colegio de México/Fondo de Cultura Económica.

López, N. (1997). La urbanización periférica. Mercado de suelo y urbanización popular en la Ciudad de Puebla, 1970-1990. (Tesis inédita de doctorado), Facultad de Arquitectura-UnAM.

Melé, P. (1994). Puebla, urbanización y políticas urbanas. México: Instituto de Ciencias-BUAP/UAM-Azcapotzalco.

Méndez, E. (1989). Urbanismo y morfología de las ciudades novohispanas: el diseño de Puebla. México: unAm.

Méndez, E. (1987). La conformación de la ciudad de Puebla (1966-1980), una visión histórica. Puebla: BUAP. 
Milián, G., y Guenet, M. (2006). Fragmentación socio-espacial y caos urbano: los vecindarios cerrados en la aglomeración de Puebla. En A. M. Séguin, La segregación socio-espacial urbana: Una mirada sobre Puebla, Puerto España, San José y San Salvador (pp. 109-146). México: Flacso/gim/uap.

Montero, C. (2002a). Colonias de Puebla. México: Instituto de Ciencias Sociales y Humanidades-BUAP.

Montero, C. (2002b). La renovación urbana. Puebla y Guadalajara: un estudio comparado. México: Instituto de Ciencias Sociales y Humanidades-BUAP.

Montero, C. (2006). Puebla en el siglo xx. En A. Allende, Puebla y el Paseo de San Francisco (pp. 211-239). Puebla: Turner.

Ovalle, I. (coord.) (1982). Necesidades esenciales en México, vol. 3: Vivienda. México: Siglo XIX/Coplamar.

pducp (1991). Programa de Desarrollo Urbano de la Ciudad de Puebla. México: H. Ayuntamiento de Puebla.

PMdusp (2005). Programa Municipal de Desarrollo Urbano Sustentable de Puebla 2005-2008. México: H. Ayuntamiento de Puebla.

Pradilla, E. (1976). Notas acerca del problema de la vivienda. Ideología y Sociedad, 16, 70-107.

puec-unam (2013). México, perfil del sector de la vivienda. México: un-Hábitat-ConAvi/Programa Universitario de Estudios sobre la Ciudad.

Rivas, J. L. de las (2008) Aprendiendo de Puebla: conservación del patrimonio urbano para una ciudad habitable. LLILAS Visiting Resource Professor Program. Recuperado de http://lanic.utexas.edu/project/etext/llilas/vrp/puebla.pdf

Robson, B. (1988). Those inner cities. Oxford: Clarendon Press.

Salamanca, J. F. (2005). Puebla (México): una ciudad histórica ante un futuro incierto. Scripta Nova. Revista Electrónica de Geografía y Ciencias Sociales, 9(194), 42. DoI: http://dx.doi.org/10.1344/sn2005.9.958

Sedesol/Conapo/Inegi (2012). Delimitación de las zonas metropolitanas de México, 2010. México: Secretaría de Desarrollo Social/Consejo Nacional de Población/ Instituto Nacional de Estadística, Geografía e Informática.

Schteingart, M. (1982). Sector inmobiliario capitalista y formas de apropiación del suelo urbano: el caso de México. En E. Pradilla (comp.), Ensayos sobre el problema de la vivienda en América Latina (pp. 449-466). México: UAM-Xochimilco.

Schteingart, M. (1989). Los productores del espacio habitable: Estado, empresa y sociedad en la ciudad de México. México: El Colegio de México. 
Sedesol, Conapo, inegi (2007). Delimitación de las zonas metropolitanas de México, 2005. México: Secretaría de Desarrollo Social/Consejo Nacional de Población/ Instituto Nacional de Estadística, Geografía e Informática.

Soja, E. (1993). Geografias Pós-modernas. A reafirmação do espaço na teoria social crítica. Río de Janeiro: Jorge Zahar.

Topalov, C. (1974). Les promoteurs inmobiliers. Contribution a l'analyse de la production capitaliste du logement en France. París-La Haya: Mouton.

Topalov, C. (1979). La urbanización capitalista. México: Edicol.

Vázquez, Y. (2007). México y Puebla; del centro comercial a la ciudad. La construcción de nuevos territorios urbanos. Trace, 51, 56-70.

Vélez, F. (2007). Planeación, crecimiento urbano y cambio social en el Centro Histórico de la Ciudad de Puebla. México: Instituto de Ciencias Sociales y Humanidades-BuAP. 
